\title{
On the limits to Ti incorporation into Si using pulsed laser melting
}

\section{Citation}

Mathews, Jay, Austin J. Akey, Daniel Recht, Girish Malladi, Harry Efstathiadis, Michael J. Aziz, and Jeffrey M. Warrender. 2014. "On the Limits to Ti Incorporation into Si Using Pulsed Laser Melting." Applied Physics Letters 104 (11) (March 17): 112102. doi:10.1063/1.4868724.

\section{Published Version}

doi: $10.1063 / 1.4868724$

\section{Permanent link}

http://nrs.harvard.edu/urn-3:HUL.InstRepos:22676989

\section{Terms of Use}

This article was downloaded from Harvard University's DASH repository, and is made available under the terms and conditions applicable to Other Posted Material, as set forth at http:// nrs.harvard.edu/urn-3:HUL.InstRepos:dash.current.terms-of-use\#LAA

\section{Share Your Story}

The Harvard community has made this article openly available.

Please share how this access benefits you. Submit a story.

Accessibility 


\title{
On the limits to $\mathrm{Ti}$ incorporation into Si using pulsed laser melting
}

\author{
Jay Mathews, ${ }^{1, a)}$ Austin J. Akey, ${ }^{2}$ Daniel Recht, ${ }^{2}$ Girish Malladi, ${ }^{3}$ Harry Efstathiadis, ${ }^{3}$ \\ Michael J. Aziz, ${ }^{2}$ and Jeffrey M. Warrender ${ }^{1}$ \\ ${ }^{1}$ U.S. Army ARDEC - Benét Laboratories, Watervliet Arsenal, New York 12189, USA \\ ${ }^{2}$ School of Engineering and Applied Sciences, Harvard University, Cambridge, Massachusetts 02138, USA \\ ${ }^{3}$ State University of New York-College of Nanoscale Science and Engineering, Albany, New York 12203, USA
}

(Received 23 January 2014; accepted 4 March 2014; published online 17 March 2014)

Fabrication of p-Si(111) layers with Ti levels well above the solid solubility limit was achieved via ion implantation of $15 \mathrm{keV}^{48} \mathrm{Ti}^{+}$at doses of $10^{12}$ to $10^{16} \mathrm{~cm}^{-2}$ followed by pulsed laser melting using a Nd:YAG laser $(\mathrm{FWHM}=6 \mathrm{~ns})$ operating at $355 \mathrm{~nm}$. All implanted layers were examined using cross-sectional transmission electron microscopy, and only the $10^{16} \mathrm{~cm}^{-2} \mathrm{Ti}$ implant dose showed evidence of Ti clustering in a microstructure with a pattern of Ti-rich zones. The liquid phase diffusivity and diffusive velocity of $\mathrm{Ti}$ in Si were estimated to be $9 \times 10^{-4} \mathrm{~cm}^{2} / \mathrm{s}$ and $(2 \pm 0.5) \times 10^{4} \mathrm{~m} / \mathrm{s}$, respectively. Using these results the morphological stability limit for planar resolidification of $\mathrm{Si}: \mathrm{Ti}$ was evaluated, and the results indicate that attaining sufficient concentrations of $\mathrm{Ti}$ in $\mathrm{Si}$ to reach the nominal Mott transition in morphologically stable plane-front solidification should occur only for velocities so high as to exceed the speed limits for crystalline regrowth in $\mathrm{Si}(111)$. (C 2014 AIP Publishing LLC. [http://dx.doi.org/10.1063/1.4868724]

Optical hyperdoping of Si via the method of ion implantation followed by pulsed laser melting (II-PLM) has recently garnered much attention as a method to incorporate impurities at levels well above equilibrium solid solubility limits. Incorporation of chalcogens into Si using this method has been shown to dramatically increase sub-band gap optical absorption, ${ }^{1,2}$ and detectors with extended spectral range have been fabricated from these materials. ${ }^{3}$ Luque et al. estimated that a Mott transition, accompanied by the formation of a metallic intermediate band (IB), should nominally occur for impurity concentrations above about $6 \times 10^{19} \mathrm{~cm}^{-3} .4$ In the case of $\mathrm{Ti}$ in $\mathrm{Si}$, this estimate may be slightly off due to spin magnetic interactions from the d-shell electrons, so we refer to this critical concentration as the "nominal" Mott limit. Recently, Olea et al. reported forming Si with high levels of Ti by II-PLM, ${ }^{5}$ suggesting the possibility of forming of an IB material using this method. ${ }^{6}$

This work explores the limit of $\mathrm{Ti}$ incorporation into $\mathrm{Si}$ under the best practically achievable laser melting conditions. Incorporation of impurities into $\mathrm{Si}$ at concentrations higher than the solid solubility limit via rapid solidification has been studied extensively. ${ }^{7-9}$ At high enough impurity concentrations, the liquid-solid interface can become morphologically unstable, leading to lateral segregation of the impurity and the formation of a cellular solidification microstructure. ${ }^{10-13}$ This process, referred to as "cellular breakdown," results in copious excess impurity located in the "cell walls."

The impurity concentration in the solid after resolidification is determined by the velocity-dependent partition coefficient, $k$, which is the ratio of impurity concentration in the growing solid to that in the liquid at the interface. In the Continuous Growth Model (CGM) for solute trapping, ${ }^{14,15} k$ for dilute solutions behaves according to

\footnotetext{
${ }^{\text {a) }}$ Author to whom correspondence should be addressed. Electronic mail: jay.mathews@udayton.edu.
}

$$
k=\frac{k_{e}+\frac{v}{v_{D}}}{1+\frac{v}{v_{D}}},
$$

where $k_{e}$ is the equilibrium partition coefficient, $v$ is the solidification velocity, and the material parameter $v_{D}$ is the diffusive velocity of the impurity in the host.

Diffusive velocities of transition metals are typically in the range of $10^{2}-10^{4} \mathrm{~m} / \mathrm{s},{ }^{13}$ and the equilibrium partition coefficient ${ }^{16}$ for Ti in Si is $2 \times 10^{-6}$, so it is clear that increasing $k$ will require high solidification velocities. The solidification velocity can be increased by decreasing the melt duration, which is strongly dependent on the temporal width of the laser pulse, provided that the melt depth is large enough that solidification does not commence until the laser pulse is over. The shorter melt duration steepens the temperature gradient experienced by the sample during solidification, allowing for more rapid rejection of latent heat. The Si:Ti material fabricated by Olea et $a l .^{5}$ was produced using a $\mathrm{KrF}^{+}$excimer laser $(248 \mathrm{~nm}$, full width half maximum $=20 \mathrm{~ns})$, which yields solidification velocities in the range of $2-5 \mathrm{~m} / \mathrm{s} .{ }^{9}$ In contrast, we use a Q-switched Nd:YAG laser $(355 \mathrm{~nm}$, full width half maximum $=6 \mathrm{~ns}$ ) for which solidification velocities are in the range of $5-10 \mathrm{~m} / \mathrm{s} .{ }^{9}$ Additionally, as the solidification front moves toward the surface, heat diffusion decreases the temperature gradient and the velocity decreases. ${ }^{17}$ Thus, shallow melt depths lead to a faster solidification velocity at the surface, within the limitation expressed above. However, the implantation and melting conditions must be chosen so the full depth of implantation damage is melted in order to allow epitaxial solidification off of the undamaged crystal underneath.

$\mathrm{Si}(111)$ wafers (p-type, boron, resistivity $1000 \Omega$-cm) were implanted with ${ }^{48} \mathrm{Ti}^{+}$at $15 \mathrm{keV}$ to doses from $10^{12} \mathrm{~cm}^{-2}$ to $10^{16} \mathrm{~cm}^{-2}$ (Cutting Edge Ions, Inc.). The (111) orientation was selected because it has been shown in the past to trap higher amounts of solute than (100). ${ }^{8}$ To minimize deep Ti penetration, implantation of ${ }^{28} \mathrm{Si}^{+}$was performed to pre-amorphize the $\mathrm{Si}$ surface, and all implantations were 
performed at a $7^{\circ}$ angle from the surface normal. The Si implantation recipe consisted of three ${ }^{28} \mathrm{Si}^{+}$implantations at energies of 9,11 , and $13 \mathrm{keV}$, each at a dose of $5 \times 10^{14} \mathrm{~cm}^{-2}$. Rutherford backscattering spectrometry in a channeling configuration (RBS-c) was performed on the implanted wafers to determine the thickness of the amorphous Si layer, and the result was input into a one dimensional heat flow simulation to determine optimal laser melting conditions. The implanted layers were laser-melted using a single pulse from a Nd:YAG laser at a fluence of $0.75 \mathrm{~J} / \mathrm{cm}^{2}$.

The fabricated Si:Ti layers were examined with highresolution scanning electron microscopy (SEM). The Ti concentration depth profiles were measured before and after laser melting using secondary ion mass spectrometry (SIMS), using the known implantation dose for calibration. Additional SIMS profiles were obtained on the three samples with the highest Ti doses in order to resolve the deeper tails of the profiles to higher accuracy. Several samples were selected for cross-sectional transmission electron microscopy (XTEM).

Figure 1 shows the Ti concentration profiles obtained by SIMS from samples implanted with selected $\mathrm{Ti}$ doses and laser melted at $0.75 \mathrm{~J} / \mathrm{cm}^{2}{ }^{18}$ For the Ti doses up to $8 \times 10^{14} \mathrm{~cm}^{-2}$, the profile has two distinct regions. Near the surface is a peak with very high concentration of Ti. This peak extends to a depth of about $20 \mathrm{~nm}$, with a slope that is identical to that of the lowest dose studied $\left(10^{12}\right.$ at. $/ \mathrm{cm}^{2}$, not shown). This slope is consistent with a known SIMS artifact associated with the finite ability of the SIMS to resolve steep concentration gradients. ${ }^{19}$ Past the surface peak the Ti profile starts to flatten out, and we see a $60-70 \mathrm{~nm}$ thick layer with retained Ti. For higher Ti doses, the surface peak is broadened, and this cannot be attributed simply to limited instrumental resolution. Profiles of this shape have been associated with the onset of cellular breakdown in which case the solidification front ceases to be planar, and excess impurity is swept into the troughs of the (initially sinusoidal) perturbation.

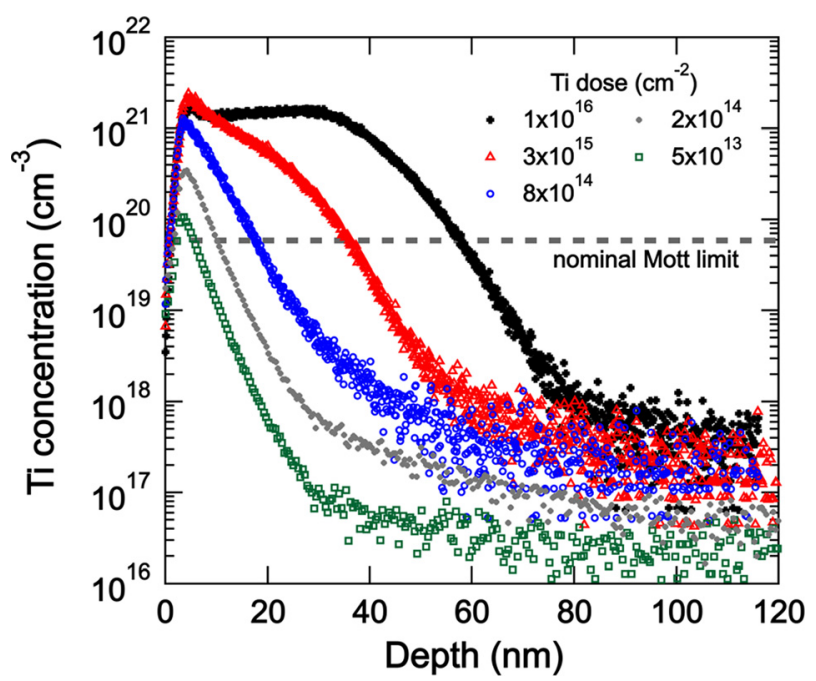

FIG. 1. SIMS Ti concentration-depth profiles obtained from p-Si(111) implanted with $15 \mathrm{keV} \mathrm{Ti}^{+}$at a variety of doses and pulsed laser melted with the Nd:YAG at $0.75 \mathrm{~J} / \mathrm{cm}^{2}$. The horizontal dashed line at $6 \times 10^{19}$ $\mathrm{Ti} / \mathrm{cm}^{3}$ identified as the "nominal Mott limit" is the estimated value from Luque et al.

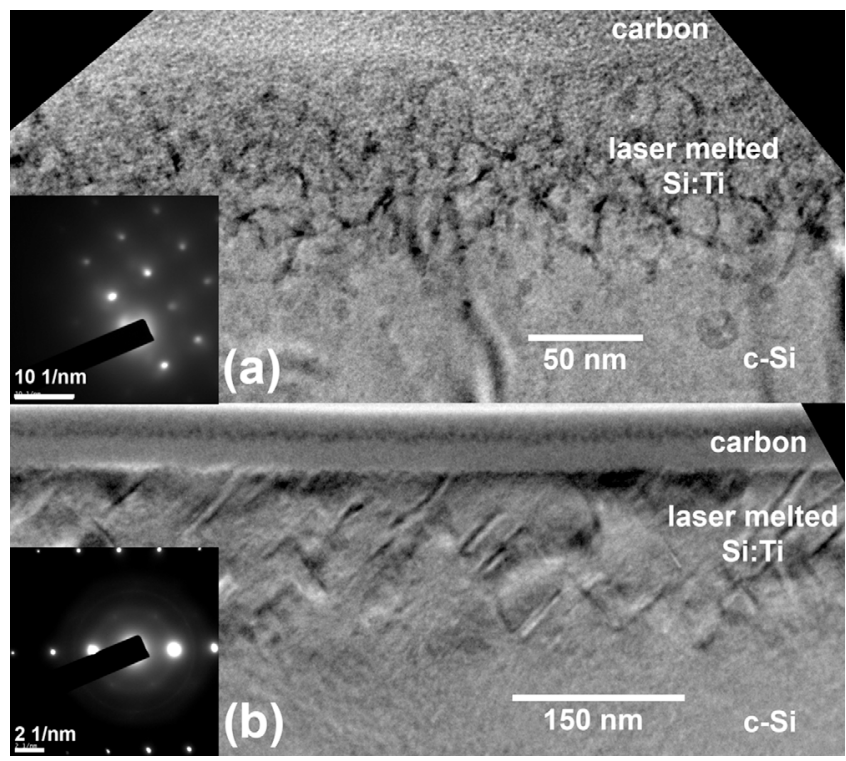

FIG. 2. Cross-section TEM micrographs of p-Si(111) implanted with $15 \mathrm{keV}$ $\mathrm{Ti}$ at doses of $1 \times 10^{16} \mathrm{~cm}^{-2}$ (a) and $3 \times 10^{15} \mathrm{~cm}^{-2}$ (b) and laser melted at a fluence of $0.75 \mathrm{~J} / \mathrm{cm}^{2}$. Insets are their respective diffraction patterns.

XTEM micrographs of the laser melted Si:Ti with the two highest doses that we studied are presented in Figure 2. The laser melted material implanted with $3 \times 10^{15} \mathrm{Ti} / \mathrm{cm}^{2}$, shown in Figure 2(b), contains extended defects starting at a depth around $140 \mathrm{~nm}$. From the orientation of these defects, it is clear that these are stacking faults; corresponding features are observed in plan-view SEM micrographs at this and all lower doses. The formation of stacking faults during the rapid solidification of $\mathrm{Si}(111)$ at high solidification speeds has been previously reported. ${ }^{20,21}$ The maximum melt depth was calculated through 1D heat flow simulations to be $150 \mathrm{~nm},{ }^{18}$ which is near the depth at which the deepest stacking faults start.

In the case of the $1 \times 10^{16} \mathrm{~cm}^{-2}$ dose (Figure 2(a)), there are defects in the laser melted area that do not appear to be stacking faults. We interpret these defects to be the result of segregation of $\mathrm{Ti}$, where the interface became unstable during solidification, producing the disordered microstructure shown in Figure 2(a).

We note that cellular breakdown, when observed in (100) $\mathrm{Si}$, typically produces cells with vertical walls, but the image of the $3 \times 10^{15} \mathrm{Ti} / \mathrm{cm}^{2}$ sample in Figure 2(b) does not exhibit that feature. It is possible that the Ti is decorating the stacking faults or forming a silicide, but the TEM diffraction pattern (inset of Figure 2(b)) does not indicate any other phases. Nevertheless, because the $3 \times 10^{15} \mathrm{Ti} / \mathrm{cm}^{2}$ sample shares the same broadened near-surface concentration feature observed for the $1 \times 10^{16} \mathrm{~cm}^{-2}$ sample in Figure 1, which is characteristic of breakdown, we tentatively identify the $3 \times 10^{15} \mathrm{Ti} / \mathrm{cm}^{2}$ material as "broken down." Previous work on $\mathrm{Sn}$ in $\mathrm{Si}$ has shown ${ }^{9}$ that cellular breakdown appears at deeper depths in the concentration-depth profile than in XTEM; in our case, the $3 \times 10^{15} \mathrm{Ti} \mathrm{cm}^{-2}$ sample may have begun to break down but reached the end of solidification before the characteristic features in XTEM were formed. Although the $3 \times 10^{15} \mathrm{Ti} \mathrm{cm}^{-2}$ sample does not show the same disordered features as does the $1 \times 10^{16} \mathrm{Ti} / \mathrm{cm}^{2}$ sample 
in XTEM, the broadened near-surface concentration in Figure 1 and the microstructure in Figure 2(b) cannot be taken as proof that $\mathrm{Ti}$ has been incorporated in homogeneous solid solution at concentrations above the Mott limit.

In order to understand how the Ti concentration profiles change during the laser melting process, we took the asimplanted Ti concentration profile obtained from SIMS $^{18}$ and numerically solved the 1D diffusion equation with partitioning at a moving boundary, following the work of Hoglund et al. ${ }^{9}$ 1-D melting, solidification, diffusion, and partitioning models have been experimentally validated for substitutional impurities in silicon, ${ }^{8,15}$ and they have recently been used to examine incorporation of other transition metals into $\mathrm{Si}^{11}$ The temporal profile of the laser pulse and the asimplanted Ti concentration profile are both used as inputs. This calculation also requires as inputs the liquid phase diffusivity of Ti in $\mathrm{Si}, D_{\text {liq }}$, and the diffusive velocity $\mathrm{v}_{\mathrm{D}}$ characterizing partitioning of $\mathrm{Ti}$ in $\mathrm{Si}$. Tang et al. reported a diffusivity of $1.12 \times 10^{-3} \mathrm{~cm}^{2} / \mathrm{s}$ for Ti in liquid $\mathrm{Si}^{22}$ which is well above the range of $2-5 \times 10^{-4} \mathrm{~cm}^{2} / \mathrm{s}$ reported for other solutes in Si by PLM by Reitano et al. ${ }^{8}$ Because it is easy to obtain erroneously high liquid diffusivities by convective contamination, we treated $D_{l i q}$ as a fitting parameter, but used the literature value for comparison. The diffusive velocity $v_{D}$ has not previously been measured for $\mathrm{Ti}$ in $\mathrm{Si}$ and was used as a fitting parameter.

Figure 3 shows the Ti concentration profiles of $p$-Si(111) implanted with $8 \times 10^{14} \mathrm{~cm}^{-2}$ before and after laser melting. The broadening of the surface peak in the experimental SIMS profile due to instrumental broadening was ignored, and the region between 20 and $130 \mathrm{~nm}$ was fit with the model. We present the two best fits from the diffusion modeling, one with $D_{\text {liq }}$ held fixed at the literature value of $1.12 \times 10^{-3}$ $\mathrm{cm}^{2} / \mathrm{s}$ and the diffusive velocity $\mathrm{v}_{\mathrm{D}}$ used as a fitting parameter, and the other with both $D_{\text {liq }}$ and $v_{D}$ used as fitting

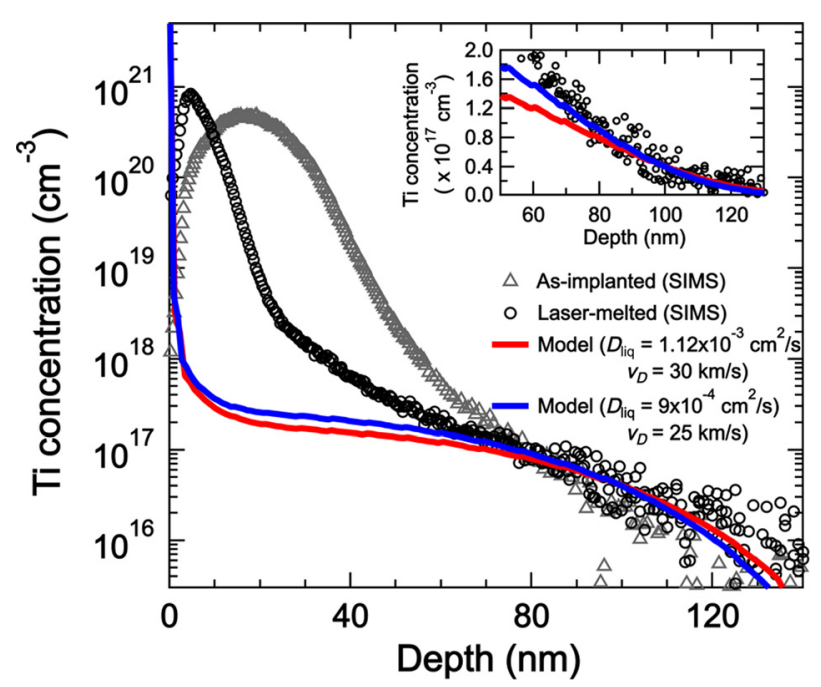

FIG. 3. Experimental as-implanted (black circles) and laser melted (grey triangles) profiles obtained using ToF-SIMS from p-Si(111) implanted with $15 \mathrm{keV} \mathrm{Ti}$ at a dose of $8 \times 10^{14} \mathrm{~cm}^{-2}$ and pulsed laser melted with the Nd:YAG. Also shown are the numerical solutions using $v_{D}=30 \mathrm{~km} / \mathrm{s}$ and $\mathrm{D}_{\text {liq }}=1.12 \times 10^{-3} \mathrm{~cm}^{2} / \mathrm{s}$ (red line), and $\mathrm{v}_{\mathrm{D}}=25 \mathrm{~km} / \mathrm{s}$ and $\mathrm{D}_{\text {liq }}=9 \times 10^{-4}$ $\mathrm{cm}^{2} / \mathrm{s}$ (blue line). Inset shows the laser-melted SIMS data with the two models on a linear scale in the region used for fitting the data with the numerical solution. parameters. In the case where the literature value is used for $D_{\text {liq }}$, the diffusive velocity was determined to be $30 \mathrm{~km} / \mathrm{s}$. However, a somewhat better fit is obtained by varying both fitting parameters, yielding the values $D_{l i q}=9 \times 10^{-4} \mathrm{~cm}^{2} / \mathrm{s}$ and $v_{D}=25 \mathrm{~km} / \mathrm{s}$. This value for $D_{\text {liq }}$ was found to provide the best fit for all doses, while the diffusive velocities for the $3 \times 10^{15} \mathrm{~cm}^{-2}$ and $1 \times 10^{16} \mathrm{~cm}^{-2}$ were found to be $22 \mathrm{~km} / \mathrm{s}$ and $15 \mathrm{~km} / \mathrm{s}$, respectively. Thus, we estimate $v_{D}$ for $\mathrm{Ti}$ in $\mathrm{Si}$ to be $(2 \pm 0.5) \times 10^{4} \mathrm{~m} / \mathrm{s}$. The SIMS concentration exhibits two features-a steady increase with decreasing depth for depths beyond $50 \mathrm{~nm}$, and an abrupt increase of several orders of magnitude beginning at about $25 \mathrm{~nm}$ - that are not reproduced in the diffusion calculations for any selection of $v_{D}$ and $D_{\text {liq }}$. The Ti concentration in the liquid remains at or below $1 \%$, so the dilute solution assumed by the calculations is reasonable. The former feature, while interesting and worthy of further exploration, is not ultimately germane to the question of whether nominal-Mott concentrations of Ti can be achieved in Si. The latter feature, the broadened surface peak, is more important, because the concentration exceeds the nominal Mott limit. To reiterate, this broadened concentration feature observed at doses of $8 \times 10^{14} \mathrm{~cm}^{-2}$ and higher is not likely to be a SIMS artifact, but cannot be explained by the CGM. We cannot conclusively say whether this high concentration of Ti is homogeneously distributed. The Ti may be located preferentially at the stacking faults, or may exist in highly localized lateral regions, corresponding to the "trough" regions in an unstable perturbation to the planar solidifying interface.

Because the deviation of the solid concentration from the predicted CGM concentration depth profile is consistent with the phenomenology of cellular breakdown, we sought to investigate whether cellular breakdown would have been expected under these solidification conditions. A necessary condition is that the concentration in the liquid away from the liquid-solid interface must exceed a critical, velocitydependent, concentration. We use the best fit values for $v_{D}$ and $D_{l i q}$ to calculate this critical bulk liquid concentration, $C_{\infty} \cdot{ }^{9}$ This method involves solving the condition at which the growth rate of a perturbation to the planar solid-liquid interface is negative for all perturbation wavelengths; i.e., where the thermal gradient and capillarity suppress the destabilizing influence of the concentration gradient in the liquid near the interface. The details of these calculations, including a plot of the neutral stability condition as a function of interface velocity, will be presented in a forthcoming paper. All Si parameters are as reported in Ref. 9. For a solidification velocity of $8 \mathrm{~m} / \mathrm{s}$, we expect the atomic fraction of $2 \times 10^{-6}$ (bulk liquid concentration of $10^{17} \mathrm{~cm}^{-3}$ ) to have been marginally stable against cellular breakdown, and higher concentrations to have been unstable. Based on our 1D diffusion calculations, all of the samples presented in Figure 1 exceeded this critical concentration before the interface reached the surface, but only the highest three concentrations show a concentration feature consistent with breakdown. However, we expect that, above the critical concentration, a perturbation that forms takes time to amplify and therefore may not become significant before solidification is complete; further exploration of this amplification time will be reported in the forthcoming paper. Our calculations also indicate that 
for a bulk liquid concentration corresponding to the nominal Mott limit to be morphologically stable, a solidification speed in excess of $100 \mathrm{~m} / \mathrm{s}$ would be required; however, this exceeds the limit of $8 \mathrm{~m} / \mathrm{s}$ above which defect-free crystalline regrowth in $\mathrm{Si}(111)$ cannot be achieved. ${ }^{23}$

In summary, the method of II-PLM was used to fabricate single crystal Si layers with Ti concentrations above the equilibrium solid solubility limit. We attempted to implement the best practically achievable experimental conditions, including shallow melting with a short laser pulse to maximize solidification velocity, use of a (111)-oriented substrate to minimize $v_{\mathrm{D}}$, and pre-amorphization prior to implantation to suppress channeling of Ti during implantation. These conditions should therefore set an upper limit on the amount of $\mathrm{Ti}$ that can be incorporated into monocrystalline Si during II-PLM. XTEM images of the laser melted layers reveal the presence of only stacking faults in the lower dose implants, while the highest dose sample $\left(10^{16}\right.$ at. $\left./ \mathrm{cm}^{3}\right)$ exhibits a cellular solidification microstructure, indicative of morphological instability during solidification. Ti concentration profiles obtained from the laser melted layers were compared with numerical simulations, and the liquid phase diffusivity was found to be $9 \times 10^{-4} \mathrm{~cm}^{2} / \mathrm{s}$, while the diffusive velocity was determined to be $(2 \pm 0.5) \times 10^{4} \mathrm{~m} / \mathrm{s}$.

Olea et al. produced layers of varying thickness with $\mathrm{Ti}$ concentrations above the nominal Mott $\operatorname{limit}^{5}$ using significantly slower solidification velocities than those achieved in the work presented here, for the same (111) orientation. The single XTEM image that they presented does not show signs of cellular breakdown. For our samples, the Ti concentration in the laser-melted layer does not exceed $10^{18} \mathrm{~cm}^{-3}$, except at the surface (for doses below $8 \times 10^{14} \mathrm{~cm}^{-2}$ ) or in a broadened peak (for doses of $8 \times 10^{14} \mathrm{~cm}^{-2}$ and above). For the highest dose $\left(1 \times 10^{16} \mathrm{~cm}^{-2}\right)$, the layer is of poor quality due to cellular breakdown. In the case of the $3 \times 10^{15} \mathrm{~cm}^{-2}$ dose, a $40 \mathrm{~nm}$ thick layer with concentration just above the nominal Mott limit, free of visible cell walls, was produced. We believe that the thickness of this layer is not attributable to a SIMS artifact. However, we are unable to say conclusively whether the Ti in this layer is uniformly distributed within the $\mathrm{Si}$, or whether, instead, it resides at the stacking faults. Even if it is distributed through the volume of the silicon instead of localized at stacking faults, it may be spatially nonuniform due to the incipient growth instability that leads eventually to cellular breakdown, but may not have had time to lead to identifiable cell walls before the solidification front reached the surface. Interface stability calculations presented suggest that the interface was indeed unstable during the solidification of both our samples and those of Olea et al., for any implant dose high enough to approach the nominal Mott limit. Because our samples solidified faster than Olea's, ours should be more stable according to stability calculations; however, ours also solidified fast enough for stacking fault incorporation, and the presence of stacking faults at the crystal/melt interface may destabilize the interface in ways that we do not fully understand. Diffusion modeling presented in Figure 3 showed that incorporation of $\mathrm{Ti}$ in greater-than-nominal-Mott concentrations in a thick layer is not expected under the CGM, which correctly described the Ti incorporation deeper in the sample. The phenomenology of the broadened peak is compatible with observations in the literature of breakdown. We are not aware of any literature reports of a solidification mechanism whereby an abrupt divergence from CGM-compatible behavior as the solidification front approaches the surface, as seen in Figure 3, is achieved without lateral inhomogeneities such as precipitation or cellular breakdown. More detailed experimental investigation, using a technique capable of resolving the lateral Ti concentration profile as a function of depth, is required to definitively establish whether the Ti has been homogenously incorporated into the $\mathrm{Si}$ in greater-than-nominal-Mott levels. Due to the stacking faults, our experiments cannot be used to conclude whether this can be achieved while avoiding precipitation or cellular breakdown. Additionally, if the estimate of the Mott transition by Luque et al. is lower than the actual limit for $\mathrm{Ti}$ in $\mathrm{Si}$, Mott levels of $\mathrm{Ti}$ in $\mathrm{Si}$ will be even more difficult to achieve. At slower solidification velocities than those reported here, such as those of Olea et al., cellular breakdown should become even more limiting for the homogeneously incorporated $\mathrm{Ti}$ concentration than it is for our conditions. Although we have not reproduced processing conditions of Olea et al., exactly, it is difficult to reconcile our experimental results, those of Olea et al., and the quantitative models of rapid solidification that describe so well the trapping of substitutional impurities in rapidly solidified silicon.

J.M. acknowledges the support from a National Research Council Research Associateship Award at U.S. Army ARDEC-Benét Laboratories. J.M.W. and J.M. gratefully acknowledge the assistance from Brian Doherty and Michael Kroko of Cutting Edge Ions in planning the Si preamorphization implantation conditions. Research at Harvard by M.J.A., D.R., and A.J.A. was supported by the U.S. Army under Contract Nos. W911NF-09-1-0118-DOD35CAP and W911NF-12-1-0196.

${ }^{1}$ S. H. Pan, D. Recht, S. Charnvanichborikarn, J. S. Williams, and M. J. Aziz, Appl. Phys. Lett. 98, 121913 (2011).

${ }^{2}$ T. G. Kim, J. M. Warrender, and M. J. Aziz, Appl. Phys. Lett. 88, 241902 (2006).

${ }^{3}$ A. J. Said, D. Recht, J. T. Sullivan, J. M. Warrender, T. Buonassisi, P. D. Persans, and M. J. Aziz, Appl. Phys. Lett. 99, 073503 (2011).

${ }^{4}$ A. Luque, A. Martí, E. Antolín, and C. Tablero, Phys. B 382, 320 (2006).

${ }^{5}$ J. Olea, M. Toledano-Luque, D. Pastor, E. San-Andrés, I. Mártil, and G. González-Díaz, J. Appl. Phys. 107, 103524 (2010).

${ }^{6}$ G. Gonzalez-Díaz, J. Olea, I. Mártil, D. Pastor, A. Martí, E. Antolín, and A. Luque, Sol. Energy Mater. Sol. Cells 93, 1668 (2009).

${ }^{7}$ C. W. White, S. R. Wilson, B. R. Appleton, and F. W. Young, Jr., J. Appl. Phys. 51, 738 (1980).

${ }^{8}$ R. Reitano, P. M. Smith, and M. J. Aziz, J. Appl. Phys. 76, 1518 (1994).

${ }^{9}$ D. E. Hoglund, M. O. Thompson, and M. J. Aziz, Phys. Rev. B 58, 189 (1998).

${ }^{10}$ C. W. White, D. M. Zehner, J. Narayan, O. W. Holland, B. R. Appleton, and S. R. Wilson, in Laser-Solid Interactions and Transient Thermal Processing of Materials, edited by J. Narayan, W. L. Brown, and R. A. Lemons (Mater. Res. Soc. Symp. Proc., Pittsburgh, 1983), p. 287.

${ }^{11}$ J. Narayan, J. Appl. Phys. 52, 1289 (1981).

${ }^{12}$ J. Narayan, J. Cryst. Growth 59, 583 (1982).

${ }^{13}$ D. Recht, M. J. Smith, S. Charnvanichborikarn, J. T. Sullivan, M. T. Winkler, J. Mathews, J. M. Warrender, T. Buonassisi, J. S. Williams, S. Gradečak, and M. J. Aziz, J. Appl. Phys. 114, 124903 (2013).

${ }^{14}$ M. J. Aziz and T. Kaplan, "Continuous growth model for alloy solidification," Acta Metall. Mater. 36, 2335 (1988).

${ }^{15}$ J. A. Kittl, P. G. Sanders, M. J. Aziz, D. P. Brunco, and M. O. Thompson, Acta Mater. 48, 4797 (2000). 
${ }^{16}$ J. R. Davis, Jr., A. Rohatgi, R. H. Hopkins, P. D. Blais, P. Rai-Chouhury, J. R. McCormick, and H. C. Mollenkopf, IEEE Trans. Electron Devices 27, 677 (1980).

${ }^{17}$ C. W. White and M. J. Aziz, in Surface Alloying by Ion, Electron, and Laser Beams, edited by L. E. Rehn, S. T. Picraux, and H. Wiedersich (American Society for Metals, Metals Park, Ohio, 1986), p. 38.

${ }^{18}$ See supplementary material at http://dx.doi.org/10.1063/1.4868724 for additional SIMS profiles, SEM micrographs, and plot of melt depth vs. time.
${ }^{19}$ J. B. Clegg and L. G. Gale, Surf. Interface Anal. 17, 190 (1991).

${ }^{20}$ A. Cullis, H. Webber, N. Chew, J. Poate, and P. Baeri, Phys. Rev. Lett. 49, 219 (1982).

${ }^{21}$ G. Foti, E. Rimini, W. Tseng, and J. Mayer, Appl. Phys. A: Mater. Sci. Process. 15, 365 (1978).

${ }^{22}$ K. Tang, E. J. Øvrelid, G. Tranell, and M. Tangstad, J. Mater. 61, 49 (2009).

${ }^{23}$ A. G. Cullis, N. G. Chew, H. C. Webber, and D. J. Smith, J. Cryst. Growth 68, 624 (1984). 